\title{
Research on the Construction of Chinese Corporate Social Responsibility Engineering System
}

\author{
Yongming Zhu, Yanmei Zhang*

\begin{abstract}
Management Engineering School, Zhengzhou University, Zhengzhou, Henan 450001, China
*Corresponding author. Email: zhuyongming@zzu.edu.cn
\end{abstract}

\begin{abstract}
The lack of sense of national responsibility and its role in this new coronary pneumonia epidemic have been concentrated, and the issue of social responsibility has once again attracted attention from all walks of life. this paper starts from the background of social responsibility development, analyzes the necessity and feasibility of the construction of corporate social responsibility engineering system; and then explores the integration mechanism of corporate social responsibility and engineering science. A preliminary exploration of the connotation and structure of the company, and build a corporate social responsibility engineering system from the theoretical, institutional, governance, cultural education and evaluation levels. The CSR engineering system proposed by the study can be used as an important means to promote the harmonious development of the government, enterprises, and the public, as well as to gain competitive advantages for enterprises. It provides certain theoretical guidance for guiding the development of CSR in China.
\end{abstract}

Keywords: Corporate social responsibility; Responsible works; System construction; Cooperative

governance

\section{DEVEIOPMENT BACKGROUND OF SOCIAL RESPONSIBILITY PROJECT}

The outbreak of covid-19 in 2020 has not only brought us great panic, but also served as a warning to all sectors of society -- social responsibility should be widely valued by all sectors of society, and social citizens' sense of social responsibility should be further valued by us. And from the many problems in the fight against the epidemic, we also realize that a set of sound corporate social responsibility engineering system is of great significance to enterprises and social institutions in the implementation of social responsibility guidance. With the deepening of the national reform and opening up, the deepening of the globalization process, the internationalization of enterprises has become a new development trend, the issue of social responsibility has attracted more and more attention from all sectors of society, and the government has gradually increased its management of social responsibility. The 18th national congress of the communist party of China (CPC) put forward the overall plan of promoting ecological progress. 18 of the fifth plenary session of much starker choices-and graver consequences-in planning and puts forward the innovation, the coordination, the development of green, open, sharing ideas, and the environmental and social governance, the formation of the government, enterprises, public tripartite work system, between the government, enterprises and individuals, such as social responsibility, adhere to the basic state policy of resource conservation and environmental protection, strengthen students' sense of social responsibility; Since then, in 2017, the report and the party's 19 September 2018 China-Africa cooperation BBS summit, the leaders are keep high attention on the issue of social responsibility, social responsibility problem was promoted to the national strategic level, and responsibility to human destiny community community concept has become a national leader's attitude to the country and the world.

And with the improvement of people's living standard, the public for Corporate Social Responsibility, Corporate Social Responsibility, hereinafter referred to as the "CSR") in the appeal also unceasingly to enhance [1], at the same time, the enterprise staff good Social Responsibility performance but also an important guarantee of enterprises to attract and retain talent [2], therefore, for the enterprise is in economic transition period, good performance of CSR is not only a Corporate response to the state and society, but also improve the management level and reputation, shaping the core competitiveness of an important means [3], is very important to the sustainable development of the enterprise. At the same time, the sense of social responsibility also ensures that the public's individual behavior is under the double constraint of moral and legal standards. Therefore, the sense of social responsibility is essential for building a socially friendly and environmentally friendly country and responsible enterprises.

More and more attention from the social from all walks of life to the social responsibility has caused many scholars research interests, through the analysis of the existing literature on CSR found that scholars from theory and existing system, corporate governance and culture, the 
evaluation of CSR are studied, but most scholars only considers the effect of single factor, a rare and other factors have merged, less from engineering point of view of research, so that is more pieces of conclusions, and lack of systematic research. In addition, other studies have shown that if consumers realize that enterprises fulfill their social responsibilities for the sake of profits, their social responsibility behaviors will have a negative impact on enterprises [4-5], that is, enterprises can only achieve good social effects if they properly fulfill their social responsibilities [3]. As a result, the concept of financial engineering and social engineering, this paper, based on sustainable development, human destiny community responsibility and community development concept, the government, enterprises and the public as the behavior main body, based on the perspective of engineering, put forward the idea of building CSR project, and carry on preliminary build of CSR, better and more effective to perform the social responsibility for the enterprise to provide theoretical foundation, strengthen corporate governance, promote better and faster development of Chinese enterprises, help to achieve the goal of people's happiness, the country rich and powerful.

\section{BACKGROUND: NECESSITY AND FEASIBIITY OF ESTABLISHING SOCIAL RESPONSIBILITY PROJECT}

\subsection{Necessity of establishing CSR project}

\subsubsection{China's need for higher and further development}

At the beginning of the China's reform and opening up, China's economic responsibility system of economic development strategy is put forward, the current economic development has been largely successful, but the accountability problem has not been implemented, to China's development has brought serious problems, such as the gap between rich and poor, environmental pollution and other issues, so that the kinetic energy of steam continued growth, sustainable development faces severe challenges. For example, China's exports to Russia in the $1990 \mathrm{~s}$, some businessmen in order to seek exorbitant profits, shoddy, commodity quality severely substandard housing, a direct impact on the Chinese products on the international reputation, especially in Europe and the United States and other developed countries, the Chinese products abroad hung up the inferior product, so that in the process of economic globalization seriously hindered the pace of the development of Chinese enterprise to the outside. In other words, the development defect of the responsibility system has seriously affected the further healthy development of China and restricted the further rapid development of China's economy. Therefore, in order to solve the principal social contradiction in the new era of China and help enterprises to develop outward, it is urgent to solve the problem of the responsibility system in a scientific and reasonable way. In addition, in March 2018, when the trade war between China and the United States began, the United States used China's inadequate fulfillment of its international responsibilities as an excuse to restrict China's electronic information and other industries. Finally, although the rise of the Internet greatly facilitate our life, but because of the emergence of large data, such as artificial intelligence, also for our personal privacy security and other issues have brought huge hidden trouble, in order to put an end to happen the citizen the problem such as information leakage, need more from a legal and moral social responsibility of relevant personnel from all walks of life, Internet companies also need to take more social responsibilities. In his New Year's message of 2018, general secretary Xi Jinping proposed that all rural poor people should be lifted out of poverty by 2020, which is a concrete practice of fulfilling the country's social responsibility. Therefore, enterprises, as the economic subject of national development, are dutybound to improve the living conditions of the people and build the international image of the country. At the same time, the international community is generally believed that social responsibility should be incorporated in the concept of business development, the core values to seek new economic growth point, developing enterprise core competitiveness is an important factor which cannot be ignored, in other words, companies want to remain competitive, must respond to changing market environment, CSR project is to establish links with other stakeholders and explore the effective way of development models. However, the current research on CSR engineering is still very weak. Although some scholars have carried out researches on CSR system, governance system and rating system, the systematic theory and ideological system of CSR engineering have not yet been formed. Therefore, the construction of a CSR engineering system to guide the development of practice is an indispensable theoretical basis for solving the shortcomings of China's responsibility system and promoting Chinese enterprises to carry out social responsibility management practices and the process of internationalization.

\subsubsection{The need for enterprises to shape their core competitiveness and develop internationally}

In recent years, the fulfillment of social responsibility has become an important driving force for the sustainable development and innovative development of enterprises [6-7]. CSR practice has become a global market development factor that enterprises need to face together, which has exerted a significant impact on consumer response, public image, information security, enterprise competitive advantage and other aspects. In order to 
establish a market competitive advantage, enterprises must respond to or actively respond to pressure from internal and external environment and fulfill their social responsibilities [8]. Moreover, the concept of CSR originated from western developed countries and has basically developed and matured. Good performance of social responsibility has become a basic access condition for foreign enterprises to enter their markets [9]. Therefore, good performance of social responsibility is essential for domestic enterprises to occupy a place in foreign countries, especially in developed countries. However, the CSR fulfillment in China is still in the initial stage of development. Among enterprises with good performance, more than $80 \%$ are state-owned enterprises, and most of them are still in a wait-and-see state. In addition, although there are some enterprises to fulfill the social responsibility, failed to achieve the ideal effect, instead of from the boycott of consumers psychological [10], and to eliminate this "lose-lose" situation, you need to effective corporate social responsibility behavior analysis and strategic management, understand the characteristics of the target group of psychological contract, with specific marketing activities, actively fulfill the social responsibility, and pay attention to social responsibility and the brand match [11], namely the social responsibility of the enterprise behavior should be based on the enterprise own development, in line with the strategic initiative behavior of consumer psychological rating, And respond effectively to the changing market environment. Therefore, the establishment of a set of scientific theoretical system to guide the implementation of CSR is crucial for Chinese enterprises in urgent need of healthy development and going abroad.

\subsection{Feasibility of establishing CSR project}

\subsubsection{The existing research content provides a theoretical basis for the establishment of CSR project}

Although the construction of CSR project does not accord with the original concept of engineering in theory, some scholars in the fields of finance and social management have been standing in the forefront of the development of modern science and technology and have studied financial engineering and social engineering. Financial engineering [12] [13] and social engineering in the field of engineering from material production to the successful practice in the field of material production to the establishment of a CSR project provides certain ideas and theoretical experience, or consider many factors, adopt the most reliable and most economical way, choose the best solution, has a great reference significance to the construction of CSR. Since the concept of CSR was proposed [14], a large number of scholars have conducted theoretical research on CSR [1517]. Domestic scholars have refined the impact of CSR from different perspectives and fields. Liu et al. believed that it is necessary to build a CSR system that conforms to the actual situation of China and reflects the relationship between various stakeholders [18]. According to the institutional theory, Yang et al. pointed out that organizations are embedded in a series of formal and informal rules ranging from mandatory political supervision to less normative pressure [19]. In other words, institutional constraints are an important guarantee for the effective operation of CSR. At the same time, Mai et al. [20] also built a theoretical approach of CSR governance based on the theory of multilateral governance to promote the "common governance" of corporate business interests and social value creation. In addition, some scholars also pointed out that strengthening the responsibility education for enterprise managers is an important way to build CSR in China [21]. Yi also believed that the education of business talents should change the educational concept [22], from skill training to quality improvement, and from profit production to responsibility. After years of exploration in the academic world, the research on CSR has been gradually enriched and refined. The research from the aspects of theory, system, corporate governance and manager education has provided a comprehensive theoretical basis for the construction of the CSR engineering system.

\subsubsection{China's existing system provides an objective basis for the establishment of CSR project}

The study found that in addition to the internal characteristics of enterprises, such as enterprise scale, financial status and business performance, which can affect the performance of CSR, institutional culture also has an important impact on the performance of CSR [23], because the behavior of enterprises is often a rational choice to adapt to the institutional environment under the established institutional environment. In addition, due to the need for the implementation of the social responsibility of the enterprise to undertake a certain cost, and its returns have certain hysteresis, mostly choose passive enterprise bear the social responsibility, therefore, some scholars put forward, and rely on voluntary CSR, from the regulation and development point of view is a mistake, the enterprise should be under the government's regulation is forced to perform the social responsibility, the responsibility should be institutionalized, with the aid of the system of binding, to ensure the feasible of CSR [24]. Zhou et al. [25] also believe that the relevant institutional environment in China should be improved to provide a sufficient incentive and constraint mechanism for the performance of CSR, so as to better improve the performance of CSR. At present, the development of social responsibility system at home and abroad has a preliminary foundation. The first international standard of ethics -- SA8000 was published in 1997, and the latest international standard of social responsibility was formally released in 2010 -- ISO26000. In October 2015, the ISO26000 PPO (Post Publication 
Organization) meeting was held, and 75 countries converted IS026000 into national standards. In the same year, based on the reference of ISO26000, China also released the first national standard document in the field of social responsibility -- the national standard of social responsibility series, which provides a unified guide for CSR disclosure in China. In addition, China's current legal systems, such as the company law, the law on the protection of consumer rights and interests, the food safety law and the environmental protection law, not only contain the content of CSR, but also contain provisions on the legal consequences of enterprises' failure to fulfill their social responsibilities. All these provide an objective basis for the construction of CSR project.

\subsubsection{The macro and micro environment of CSR project construction has begun to emerge}

In order to adapt to the increasingly complex and competitive market environment and gain the trust of consumers, investors and other stakeholders, more and more enterprises are integrating social responsibility into their development strategies and disclosing CSR information, so as to increase their economic and social benefits through good social responsibility performance. The introduction of the national "five-in-one" overall layout strategy has put forward mandatory requirements for enterprises' social responsibility behaviors and provided a macro political environment for the construction of CSR projects. The release of the first series of national standards on social responsibility in China has provided basic norms for enterprises to compile their reports on social responsibility performance, greatly facilitated the evaluation of social citizens on their responsibility performance, and laid a foundation for the construction of the evaluation system. According to embellish the spirit of universal responsibility rating (PKS) test, according to A report in 2018, Shanghai and Shenzhen two city A total of 851 a-share listed companies to disclose its annual CSR report, "2019" golden bee corporate social responsibility report China index show that from January to October 2019 social responsibility report released A total of 1993 in China, the enterprises accounted for $95.9 \%$, in A report every year at the Chinese academy of social sciences published "China corporate social responsibility report", but also to the large enterprise social responsibility development index in China year by year tracking, fully revealed the social responsibility of large enterprises in China. In addition, in recent years, the media for a series of food safety accidents, coal safety accident and public welfare undertakings, such as focus and reports of the accident responsibility, social responsibility has been wide attention by the public media, the influence and credibility of the media as a medium for the feasibility of the engineering system for the construction of the social responsibility of a hotbed. Therefore, from the perspective of practice, the macro- environment and micro-environment of CSR project construction are also emerging.

\section{CONNOTATION OF CSR PROJECT}

To explore the connotation of CSR engineering, we should first interpret what "engineering" is, which is the basis of analyzing the system elements and structure content of CSR engineering. The traditional definition of engineering is the process by which an organized group of people, using relevant scientific knowledge and technical means, transforms an existing entity into a man-made product for the purpose of achieving a certain goal. And in order to better adapt to the development of science and technology, scholars put forward the concept of modern engineering, and has produced a large number of achievements, such as system engineering, management, engineering, social engineering, etc., as a result, the meaning of engineering with large extension, includes not only the basic elements such as organization management, coordination, economy, and must also coordinate the social, political, legal, cultural, and environmental and other factors [26]. And the construction of corporate social responsibility is a directly related to economic modernization and building a harmonious society, improve people's happiness index of complicated system engineering, the use of scientific knowledge, through modern technology means to coordinate political, economic, legal, cultural, and environmental factors, such as implementing enterprise better fulfill the social responsibility of a project, is the expansion and extension of modern engineering, project delivery of its products include not only the reality, and is more specific, the larger social activities [27], such as charity, community activities, social responsibility report, etc.

According to the stakeholder theory, an enterprise is a "group of contracts" concluded by all stakeholders [28-29]. Thus it can be said that enterprises are not only subordinate to shareholders, but also the community of stakeholders. The material basis for the enterprise, the development model, the ownership arrangement, goal pursuit is not only related to the shareholders, is more closely related to the various stakeholders [30], the social responsibility is higher than the organization goal of his social obligation, namely CSR at the same time, coordinate the interests of the enterprise in the pursuit of the interests of other stakeholders, in the process of creating economic benefits for the enterprise development, promote social harmony and stability in the On the premise of consuming their own interests, only through the benign interaction between government policy guidance, public media supervision and enterprise self-discipline can enterprises break through the obstacles in the process of CSR performance and achieve ideal results in promoting CSR performance [31]. Therefore, the integration of CSR and engineering aims to build a concrete implementation mechanism with the engineering science and social science as the underlying structure, with the government as the guide, the enterprise as the core and the public as the 
supervision subject, so as to promote the harmonious development between enterprises and stakeholders, further expand the connotation of CSR and promote the implementation of CSR.

Therefore, this paper puts forward the concept of Corporate Social Responsibility Engineering (CSRE), which means to plan and solve the fulfillment of Corporate Social Responsibility by Engineering means. That in order to achieve the economic and social benefits of the enterprise, to the enterprise as the behavior main body, the government as the main body in the policy guidance, as a main body social public supervision, from the perspective of internal and external stakeholders, draw lessons from the theory and methods of financial engineering and social engineering, to enterprises to take stakeholders (shareholders, employees, suppliers, customers, environment, society, etc.) the responsibility as the guidance, to the construction of the specific performance of the mechanism for content, study and explore the development of CSR management model, the theory and methods of comprehensive utilization of the related scientific theories and social resources, and build and choose the specific model and direction of the development of the enterprise, Find out the system and policy to solve the conflict between the enterprise and the stakeholders, so as to maximize the effect of CSR.

\section{CSRE SYSTEM CONSTRUCTION}

At present, issues related to economics, politics, management, systems, policies, ethics, laws, etc. are all engineering social issues, and engineering pays attention to theory and practice. Engineering practice can generally be determined by engineering activities, engineering subjects and engineering achievements Three aspects to illustrate. When engineering is a design process, the theory and system are the bottom building of the entire engineering activity, which guarantees the theoretical basis and feasibility of the engineering activity and ensures that the engineering activity operates within certain rules and regulations [32].Engineering is a practical process, and the implementation of CSR is also a practical process. Whether it is forced to respond or the company takes the initiative, it has become part of the company's microgovernance behavior and is embedded in corporate governance [33]. For CSRE, governance is a part of the main body of the project; while human beings are the main body of social activities, they are not only the initiators and planners of the project activities, but also ensure the smooth implementation and completion of the project activities, while strengthening the CSR of social personnel Cultural education is an important way for China's CSR construction. It restricts the personnel involved in CSR activities from the moral and ethical level. Therefore, to ensure the smooth progress of CSRE, the cultural education of the actors is also part of the project. Finally, the completion of the entire engineering activity is evaluated, information is collected and collected, and the evaluation results are fed back in time to facilitate the better implementation of the next engineering activity. Therefore, the CSRE evaluation report constitutes the achievement part of the project. In summary, this article intends to initially construct a CSRE system from five aspects: theory, system, governance, cultural education, and evaluation, to provide theoretical and practical guidance for Chinese companies to better perform CSR. The relationship diagram of the corporate social responsibility engineering system is shown in Figure 1:

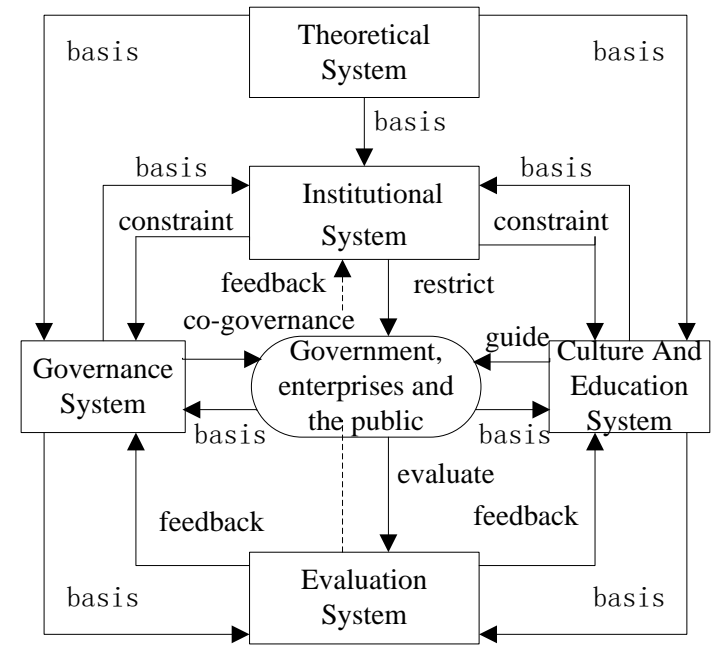

Figure 1 Corporate social responsibility engineering system diagram

The construction of theoretical system provides the theoretical basis for the construction of CSRE system. On this basis, based on the actual governance of the government, enterprises and the public, the existing issues of social responsibility governance are summarized, and the governance system of CSRE system is constructed. Based on this, the co-governance model of government, enterprises and the public is carried out, and the basic conditions are provided for the construction of the institutional system and the evaluation system. Based on the theoretical system and the cultural and educational background of the government, enterprises and the public, the cultural and educational system is constructed, and the cultural and educational issues of social responsibility of the government, enterprises and the public are reversely guided, so as to provide basic conditions for the construction of the institutional system and the evaluation system. On the basis of theory, governance and education system, an institutional system should be established to define the responsibility boundary of government, enterprise and public governance scope, regulate their responsibility behaviors, reverse constrain the governance system and education system, and formulate their rules and regulations on the basis of the institutional system. Finally, the evaluation system is constructed. 


\subsection{CSRE Theoretical System}

The theoretical system mainly includes the origin of the basic theory, the theoretical construction of CSRE and the development of the theoretical system of CSRE with Chinese characteristics. First of all, through the social responsibility theory research at home and abroad, summarized refined scholars to research on social responsibility are applied to some of the basic theory, such as stakeholder theory, resource dependence theory, corporate citizenship theory, division of labor theory, fair theory, game theory, the system integration, in order to serve the whole project system. These basic theories are the building blocks of CSRE. Secondly, combining with engineering to define the CSRE boundary, define the connotation, clarify the mechanism and value, analyze the elements and hierarchical structure, and identify the influencing factors, so as to form a complete theoretical guidance system from a systematic perspective. Finally, on the basis of not violating international norms, and in combination with China's national conditions, the theoretical system of CSRE should be constructed to keep pace with The Times.

\subsection{CSRE Institutional System}

A sound legal system is a mandatory means to ensure the good performance of CSR. The construction and implementation of a reasonable CSRE are also inseparable from complete rules and regulations. Moreover, the system has the coercive power to regulate, motivate and constrain the social behaviors of enterprises, which can effectively promote the rational allocation of social resources. From the fight against the new pneumonia epidemic, we can also see that the central government issued a series of institutional policies to effectively contain the vicious spread of the epidemic, to ensure the smooth progress of the anti-epidemic campaign. Therefore, this paper believes that the construction of CSRE system includes the formulation, implementation and implementation of relevant national policies such as fiscal and tax systems, environmental protection systems and legal systems, as well as the establishment of enterprise management systems (including internal control systems and incentive systems). From the perspective of administration, the relevant national and local administrative departments should first improve the capacity of system supply and solve the problems of system shortage and system failure. Secondly, the enterprise has set up a special department responsible for social responsibility engineering work, which strictly follows various laws and regulations, coordinates the differences and values among various stakeholders, and builds consensus and standardizes behaviors. Finally accelerate the pace of institutional innovation in government laws and regulations, on the basis of combining with the development strategy of the company set up suitable for the company's internal rules and regulations, implement system supply is practical and forward-looking, especially for quality supervision and employee benefits (good working environment, regular training education, pay attention to employees' physical and mental health, etc.), in the protection of the interests of the enterprise at the same time, to assure responsibility for consumers and employees; And the establishment of the corresponding supervision group, in order to achieve the goal of system implementation.

\subsection{CSRE Governance System}

The construction of CSRE governance system needs to rely on a multi-dimensional structure, which is composed of a combination of law enforcement, administrative intervention, state macro-control, enterprise internal governance, and social group supervision, etc. In addition, the whole governance process is legalized, institutionalized, standardized, specialized, and transparent. First of all, social responsibility governance is a process, coordination and control is the starting point of governance. Social responsibility governance emphasizes the diversification of subjects, which involves not only the national government and the public sector, but also individuals or for-profit organizations, and requires the continuous cooperation of all relevant subjects. Second, the government, enterprises and the public role more and more prominent in the field of social responsibility, for example in social environmental protection, the government in the performance of their responsibility to protect our environment at the same time, enterprises should strengthen corporate governance, improve the methods of production, energy conservation and emission reduction, the public also should strengthen environmental protection consciousness, care for the environment, pay attention to when conducting business activities high efficiency and energy saving, the three supervise each other, promote each other in the performance of the mechanism. Therefore, the co-governance network of social responsibility projects not only needs the benign interaction between the government, enterprises and the public, but also needs the cooperation between the government, enterprises and the public, mutual supervision and coordination to improve the problems that need to be solved in social responsibility, so as to form an effective governance system of cooperation among the government, enterprises and the public.

\subsection{CSRE Culture and Education System}

CSRE culture and education system should provide social citizens with social responsibility culture education at different stages from the state, schools and enterprises. The state attaches great importance to the publicity and education of the culture of social responsibility, such as the traditional fine culture and the core socialist values and new ideas, so as to build up the people's sense of national fine cultural honor and sense of social responsibility. 
Schools should give full play to their educational advantages and cultivate students' good sense of social responsibility. First, establish the concept of responsibility, clear responsibility content, clear rights sharing and responsibility sharing, adhere to the fine traditional culture and modern socialist core values unified education, to help students form the correct values; Secondly, we should cultivate their civic consciousness and enhance the concept of equal rights and responsibilities. Strengthen cooperative governance education, clarify responsibility attribution; Finally, the combination of theory and practice enables students to feel their social responsibilities in practice, and to develop students' good habits from passive acceptance to active learning. Corporate social responsibility is the concentrated embodiment of civil society responsibility, and enterprises with responsibility can train more responsible employees. At the enterprise level, therefore, can be through the cooperation between colleges and other ways to let the students, especially business students, access to the enterprise for further cooperation and communication, and through the enterprise training for students and employees such as enterprise culture, and in view of the enterprise internationalization strategy, understand the docking system of country's cultural environment and culture, etc., let the students feel in the real environment, the business environment, in turn, collisions with their own ideas fusion, preparing to develop a responsible leader.

\subsection{CSRE Evaluation System}

The construction of CSRE evaluation system is an important means to enhance the ability of enterprises to perform their duties and ensure the effective operation of CSRE. At the same time, the concept of scientific development has penetrated into all aspects of development, and enterprises and countries pay more attention to comprehensive, coordinated and sustainable development. Therefore, the introduction of sustainable development is a further improvement of the evaluation system of CSR. In the construction of the evaluation system, firstly, it follows the principles of science, rationality, comprehensiveness and operability, takes into account the heterogeneity of the industry and the situation of time series, and USES the entropy weight method to assign weights to the indicators to avoid subjective evaluation. Secondly, based on the existing research results and based on the structural equation model (SEM), five dimensions (government performance, enterprise performance, citizen performance, responsible governance and sustainable development) of social responsibility fulfillment are established. Based on the ISO26000 guide to social responsibility and China's series of national standards for social responsibility, it considers eight aspects (responsible governance, human rights, economic development, labor practices, environment, fair operation, consumer issues and community development). Then, a set of comprehensive and highly applicable social responsibility evaluation system is constructed by using qualitative and quantitative analysis. Finally, a feedback system is constructed according to the evaluation system, and the CSRE system is constantly improved, so as to form a dynamic evaluation system that is constantly improved and in line with China's national conditions.

\section{STRATEGIC SIGNIFICANCE OF CSRE SYSTEM CONSTRUCTION}

According to the theories of stakeholder and synergetic effect, CSR can not only promote the financial performance of enterprises, but also inhibit the financial performance of enterprises. However, active fulfillment of social responsibility will not only bring positive influence to the modern society and the country, but also be of vital importance to the development of future generations. With the convening of the 18th national congress of the communist party of China (CPC) and the 19th national congress of the communist party of China (CPC), China has elevated social responsibility to the strategic level of national development, and launched a series of national standards on social responsibility to guide enterprises to fulfill their social responsibility. In China, more and more enterprises begin to disclose social responsibility information. Therefore, it is of great strategic significance to actively promote the construction of CSRE system at this time. Meanwhile, the construction of CSRE system has corresponding advantages for enterprises, society and the country:

We will promote common governance and ensure competitive advantage. The pros and cons of enterprise management mainly depend on the degree of perfection of corporate governance mechanism. Corporate governance has a complicated relationship with the implementation of CSR, and the two are interrelated and interact with each other. Enterprises actively undertake social responsibilities, which is conducive to enhancing the contact and trust with relevant stakeholders, increasing the participation of stakeholders, reducing information asymmetry and agency costs, so as to achieve sustainable development of enterprises. At the same time, it redefines the role of CSR in corporate governance from the perspective of engineering, and integrates social responsibility into the theory and practice of corporate governance, which not only lays the theoretical foundation for the integration of corporate governance and CSR, but also increases the competitiveness of enterprises and guarantees their competitive advantages.

We will raise awareness of responsibility and improve public oversight. The establishment of CSRE system increases the mandatory constraint on enterprises at the institutional level and strengthens the fulfillment consciousness of citizens at the moral level. The emphasis on the "responsibility oriented" value creation model for talents is not only conducive to rectifying corporate social behaviors, but also conducive to promoting the coordination between organizational and individual behavioral goals and social goals, so that enterprises can 
gradually enhance their sense of responsibility in the behavioral constraints. At the same time, the main purpose of CSR is to meet people's needs and put people first. CSRE system, from the perspective of corporate, government and social tripartite cooperative governance, restrains, educates and guides the subject of behavior to meet the public demand, further improves the social supervision mechanism and improves the overall level of CSR in China.

To increase social well-being and adapt to the international environment. The fulfillment of corporate social responsibility is conducive to improving people's livelihood, increasing social capital and corporate soft resources, thus contributing to the construction of a harmonious society.In the external market environment, there is a symbiotic relationship between the enterprise and its competitors, realizing the most fundamental interest exchange. If the competition is more sufficient, the symbiosis will be higher, the survival cost will be lower, the overall social well-being will be improved, and the benign symbiotic competition will be realized. At the same time, the active implementation of corporate social responsibility is also to adapt to the changing international political and economic environment. With the deepening development of economic globalization, the global village model has become more and more prominent. The consumer range of major enterprises has been extended to all parts of the world, and the international competition has become increasingly fierce. In order to gain a favorable position in the international competitive environment, enterprises must actively undertake social responsibilities, establish a good image of performing their duties in the international market, and cultivate new competitive advantages.

\section{CONCLUSION}

Under the concept of comprehensively deepening reform and scientific development, fulfilling social responsibilities has become an important driving force for promoting sustainable and innovative development of enterprises, adding social well-being, and improving national governance capabilities. The CSER system proposed in this article guides companies to plan, implement and evaluate social responsibilities from a strategic level, helps companies transition from passive fulfillment to proactive attack, caters to the concept of scientific development in China, and promotes the harmonious development of government, enterprises and the public, thus Help companies win their advantages in international competition.

\section{ACKNOWLEDGMENT}

This work is supported by the Ministry of Education Humanities and Social Sciences Planning Fund Project "Research on the Cross-border E-commerce Platform
Corporate Social Responsibility Governance Path under the Sharing Economy" (20YJA630101).

\section{REFERENCES}

[1] Lu D, Powpaka S., Li YC. (2009) Review of Corporate Social Responsibility Communication Strategies Based on Meaning Construction Theory. J. Foreign Economy and Management, 31: 18-24.

[2] He K. (2018) Research on the impact of corporate employee responsibility on organizational citizenship behavior of new generation employees. J. Management Journal, 31: 33-43.

[3] Xu Z, Li X. (2018) Design of Coupling Promotion Mechanism for Corporate Social Responsibility. J. Macroeconomic Research, (01): 146-155.

[4] Yoon Y., GÜRHAN- Canli Z., SCHWARZ N.. (2006) The Effect of Corporate Social Responsibility (CSR) Activities on Companies with Bad Reputations[J]. Journal of Consumer Psychology,16: 377- 390.

[5] WAGNER T., LUTZ R. J., WEITZ B. A..(2009)Corporate Hypocrisy: Overcoming the Threat of Inconsistent Corporate Social Responsibility Perceptions. J. Journal of Marketing, 73: 77- 91.

[6] Zheng Q, Lu Y. (2018) "Follow the waves" or "Strategic choice": A study on the response mechanism of corporate social responsibility. J. Nankai Management Review, 21: 169-181.

[7] Leng J, Gao Y. (2019) Corporate Social Responsibility Information Disclosure Quality and Innovation Sustainability under Financing Constraints_-Data Analysis of Small and Mediumsized Board Enterprises. J. Science and Technology Progress and Countermeasures, 36: 77-84.

[8] Zilberg T. (2010) CSR Contribution to management in the 21st century. J. Managerial Challenges of the Contemporary Society, (1): 239-243.

[9] Wang Q, Li Q. (2015) Corporate Social Responsibility Value Creation Mechanism and Empirical Test—Based on the Perspective of Supply Chain. J. Macroeconomic Research, (01): 116-127.

[10] Deng, X. (2012). Understanding Consumer's Responses to Enterprise's Ethical Behaviors: An Investigation in China. J. Journal of Business Ethics, 107(2), 159-181. 
[11] Deng X, Long X, Liu Y, Ye Z. (2017) Is there any good reward for good deeds-Research on the internal mechanism of consumers resisting corporate social responsibility. J. Nankai Management Review, 20: $129-139$.

[12] Wang J. (2004) Discussion on the Construction of Financial Engineering Discipline. J. Finance and Economics, (6): 12-14.

[13] Huang S. Qian X. (2013) Social engineering ideas and methods and their significance. J. Journal of Renmin University of China, (4): 98-104.

[14] Sheldon, O. (1924) The Philosophy of Management. M. London: Sir Isaac Pitman and Sons Ltd. : 151-155.

[15] Brown, H R.. (1953) Social Responsibility of the Businessman. M. Harper \& Row: New York, : 128-130.

[16] Davis, K. (1960) Can business afford to ignore social responsibilities? J. California Management Review, (2): 70-76.

[17] Carroll, A. B.. (1979) A three-dimensional conceptual model of corporate performance. J. The Academy of Management Review, 4: 497-505.

[18] Liu W, Tang L. (2009) Construction of China's Corporate Social Responsibility System. J. Journal of Beijing Technology and Business University: Social Science Edition, (5): 28-33.

[19] Yang H, Wu D, Li X. (2012) Analysis of the characteristics of corporate social responsibility information disclosure herd effect. J. Finance and Accounting: Financial Management Edition, (8): 61-63.

[20] Mai S, Yang Y, Li J. (2015) Corporate Social Responsibility Governance: A Theoretical Model of Multi-Theory Fusion. J. Management Review, (6): 100110.

[21] Liu G. (2009) The status quo of MBA corporate social responsibility education and its optimization countermeasures_-Based on a questionnaire survey of MBA students. J. China Higher Education Research, (11): 25-28.

[22] Yi K. (2012) Corporate Social Responsibility Education for Business Talents: Ideas, Dilemmas and Countermeasures. J. Educational Research, 33: 152157.

[23] GJøLBERG M. (2009) Measuring the immeasurable?: Constructing an index of CSR practices and CSR performance in 20 countries. J. Scandinavian journal of management, 25: 10-22.

[24] Yang L. (2014) Institutionalization of Corporate Social Responsibility. J. Legal Research, 36: 131-158.

[25] Zhou Z, He D, Li Z. (2012) Institutional environment and corporate social responsibility fulfillment: empirical evidence from Chinese listed companies. J. China Soft Science, (10): 59-68.

[26] Cheng G, Liu F. (2004) Modern Engineering and Engineering Ethics. J. Journal of Xi'an Jiaotong University (Social Science Edition), (03): 26-30.

[27] Li B. (2002) Efforts to open up to the field of engineering philosophy. J. Dialectics of Nature, (07): 36-39.

[28] Fensen M, Mechlihg W. (1976) Theory of the firm: managerial behavior, agency costs and capital structure. J. Journal of Financial Economics, 3(4).

[29] Freeman R E, Evan W M. (1990) Corporate governance: A stakeholder interpretation. J. Journal of behavioral economics, 19: 337-359.

[30] Zhang Z, Jin X, Li G. (2013) An empirical study on the inter-temporal impact of the interaction between corporate social responsibility and financial performance. J. Accounting Research, (08): 32-39..

[31] Wang S, Li K. (2009) Deconstruction of Corporate Social Responsibility: Logical Starting Point, Conceptual Model and Performance Essentials. J. Foreign Economy and Management, 31: 25-31 + 51 .

[32] Xue S. (2016) Engineering PhilosophyPerspective of Engineering Nature. M. Beijing: Science Press.

[33] Xiao H, Yang Z. (2018) Mutual Benefit Enterprise: The Desirable Organization Paradigm of Social Responsibility Practice. J. China Industrial Economy, (07): 174-192. 